\title{
Tungsten oxide nanowires grown on amorphous-like tungsten films
}

\author{
D Dellasega ${ }^{1}$, S M Pietralunga ${ }^{2}$, A Pezzoli ${ }^{1}$, V Russo ${ }^{1}$, L Nasi $^{3}$, \\ C Conti ${ }^{4}$, M J Vahid ${ }^{5}$, A Tagliaferri ${ }^{5}$ and M Passoni ${ }^{1}$ \\ ${ }^{1}$ Dipartimento di Energia, Politecnico di Milano, via Ponzio 34/3, 20133 Milano, \\ Italy \\ 2 IFN, CNR, Piazza Leonardo da Vinci 32, 20133 Milano, Italy \\ ${ }^{3}$ IMEM, CNR, Parco Area delle Scienze 37/A, 43124 Parma, Italy \\ ${ }^{4}$ ICVBC, CNR, Via R. Cozzi 53, 20125 Milano, Italy \\ ${ }^{5}$ Dipartimento di Fisica, Politecnico di Milano, Piazza Leonardo da Vinci 32, 20133 \\ Milano, Italy \\ E-mail: david.dellasega@polimi.it
}

\begin{abstract}
Tungsten oxide nanowires have been synthesized by vacuum annealing in the range $500^{\circ} \mathrm{C}-710^{\circ} \mathrm{C}$ from amorphous-like tungsten films, deposited on a $\mathrm{Si}(100)$ substrate by Pulsed Laser Deposition (PLD) in presence of a He background pressure. The oxygen required for the nanowires formation is already adsorbed in the $\mathrm{W}$ matrix before annealing, its amount depending on deposition parameters. Nanowire crystalline phase and stoichiometry depend on annealing temperature, ranging from $\mathrm{W}_{18} \mathrm{O}_{49^{-}}$ Magneli phase to monoclinic $\mathrm{WO}_{3}$. Sufficiently long annealing induces the formation of micrometer long nanowires, up to $3.6 \mu \mathrm{m}$ with an aspect ratio up to 100 . Oxide nanowires growth appears to be triggered by the crystallization of the underlying amorphous $\mathrm{W}$ film, promoting their synthesis at low temperatures.
\end{abstract}




\section{Introduction}

The unique electronic and electro-chromic properties of nanostructured tungsten oxides and in particular of tungsten oxide nanowires (NWs) make them interesting for applications in many technological fields such as gas and $\mathrm{pH}$ sensing $[1,2,3]$, water splitting [4] and field emission [5, 6, 7]. The preparation methods of NWs may follow different strategies: direct growth of NWs during thermal treatment from a tungsten surface (W) exposed to an inert gas containing oxygen impurities [8, 9, 10, 11, 12]; vapor phase growth on several substrates (e.g. carbon fibers) starting from a tungsten oxide $\left(\mathrm{WO}_{x}\right)$ source $[13,14,15]$; solvothermal synthesis of metal-organic compounds [16, 17]; annealing of $\mathrm{WO}_{x}$ in reducing atmosphere [2].

Among these processes of synthesis, the direct growth method has attracted much attention due to its simplicity and the high degree of crystallinity of the obtained products. NWs direct growth depends on several process parameters: annealing temperature, W surface morphology, presence and stoichiometry of $\mathrm{WO}_{x}$, etc. $[11,18]$. Despite the variety of successful approaches, a well assessed growth model is absent and the dynamics that lead to the NWs formation are not fully understood yet. The presence of oxygen at very low concentration in the inert gas is essential for the production of NWs [19]. The relevance of the oxidation state of the W surface before the NWs synthesis (oxidized $\mathrm{W}$ vs non-oxidized $\mathrm{W}$ ) is still matter of debate $[9,5]$. In the works by Klinke et al. [10] and Yu et al. [20], related to the formation of W oxide NWs and ZnO needles, a possible driving force for NWs growth is suggested to be related to the formation of a stressed state at the interface between surface oxide and bulk metal, due to physical or chemical modifications of the system (e.g. formation of $\mathrm{W}$ compounds like tungsten carbide). In such situation the NWs growth would allow the relaxation of the strained oxide at the $\mathrm{W} / \mathrm{WO}_{x}$ interface.

The growth of NWs directly from W films deposited on silicon substrates might pave the way to the integration of NWs on silicon chips. However the synthesis of NWs usually occurs at high temperatures $\left(650-1300^{\circ} \mathrm{C}\right)$ [11] and this may limit their applicability to the semiconductor technology. Above $750^{\circ} \mathrm{C}$ NWs sublimation takes place, preventing the formation of micrometer long NWs [19]. The lowering of the reaction temperature is therefore one of the main goals in tungsten NWs production. One route is to start from $\mathrm{W}$ compounds, like $\mathrm{W}_{2} \mathrm{~N}$, instead of metallic $\mathrm{W}$. Using this kind of material the reaction temperature ranges between $600-700^{\circ} \mathrm{C}$. NWs with length between $250 \mathrm{~nm}$ and $1 \mu \mathrm{m}$ are obtained if sufficiently long annealing time is adopted. However, even at $600-700^{\circ} \mathrm{C}$, beyond a certain critical size the sublimation rate of the NWs overcomes the deposition rate limiting the attainable NWs length and density [18].

We propose a new growth strategy for NWs of tungsten oxide, which relies on vacuum annealing of metastable defective $\mathrm{W}$ structures, like nanostructured or amorphous metallic tungsten. Recently, thanks to the use of Pulsed Laser Deposition (PLD), an out of equilibrium physical vapor deposition technique, it has been demonstrated the possibility of depositing micrometer thick films of amorphous-like metallic W (a-W) 
with variable oxygen content [21]. Thanks to the out of equilibrium structure and to the rather peculiar presence of a large quantity of unbound oxygen within the a-W matrix, the growth of micrometer long tungsten oxide NWs takes place after a simple annealing in vacuum at temperatures in the range $500^{\circ} \mathrm{C}-710^{\circ} \mathrm{C}$. Due to the disordered nature of the amorphous-like material film, crystallization occurs at much lower temperatures compared with microcrystalline $\mathrm{W}[22]$, thus promoting the formation of local stresses at the surface of the a-W film at low temperatures. The NWs properties depend on the oxygen content and surface state of the a-W films. NWs growth and stoichiometry, at varying temperature and duration of the annealing, have been investigated.

\section{Experimental}

Amorphous-like W films are deposited using PLD. In our experiments nanosecond laser pulses at $\lambda=532 \mathrm{~nm}, 7 \mathrm{~ns}$ of temporal duration and $815 \mathrm{~mJ}$ of energy per pulse are focused on a 2 inch diameter $\mathrm{W}$ target. The species ablated from the target expand in a vacuum chamber reaching a base pressure of $10^{-3} \mathrm{~Pa}$, where a He background gas pressure of 40-75 $\mathrm{Pa}$ is present. The expanding species are collected on a substrate, silicon (100), positioned $60 \mathrm{~mm}$ away from the target. The presence of He in a proper pressure range determines the deposition of amorphous-like compact films of $\mathrm{W}$; further details are reported in [21]. The deposited films have been annealed in vacuum (base pressure $10^{-5} \mathrm{~Pa}$ ), by ranging the temperature between $200^{\circ} \mathrm{C}$ and $710^{\circ} \mathrm{C}$; annealing time varies between 4 and 10 hours. Film structure and morphology have been characterized by XRD, using a Panalytical X'Pert PRO X-ray diffractometer in $\theta / 2 \theta$ configuration, and with a Zeiss Supra 40 Field Emission Scanning Electron Microscope (SEM, accelerating voltage 3-5 kV). In order to check film composition, we performed Energy Dispersion Spectroscopy analysis (EDS) using an accelerating voltage of $5 \mathrm{kV}$, to excite $\mathrm{M}_{\alpha}$ and $\mathrm{K}_{\alpha}$ electronic levels of $\mathrm{W}$ and $\mathrm{O}$ respectively. The inspected thickness range is about $100 \mathrm{~nm}$, depending on the penetration depth of electrons and

the density of the W films. Stoichiometry and crystallinity of the annealed samples have been investigated by Raman Spectroscopy using a Renishaw InVia spectrometer in backscattering geometry. The using excitation wavelength is $514.5 \mathrm{~nm}$ from an $\mathrm{Ar}$ ion laser. HRTEM analysis on NWs were performed by a Jeol 2200FS field emission gun microscope, working at $200 \mathrm{kV}$. Local compositional analysis of the samples, at surface and in depth, and check for oxidized phases were performed by UHV Scanning Auger Microscopy (SAM) (PHI 660) [23]. Measurements were taken at V $=10 \mathrm{kV}$ of accelerating voltage, $\mathrm{I}=10 \mathrm{nA}$ of electron beam current and with an energy resolution of $\Delta \mathrm{E} / \mathrm{E}=0.5 \%$. Sputtering by Argon ion beam $(\mathrm{V}=4 \mathrm{kV}, \mathrm{I}=1 \mu \mathrm{A})$ was used to remove contaminants (mainly Carbon) from sample surface. Preliminary, Auger spectra were measured on metallic $\mathrm{W}$ wire and crystalline $\mathrm{WO}_{3}$ samples as standards for tungsten, respectively in the pure and oxidized phase. Since $\mathrm{W}$ oxides might be subject to electron beam damaging (reduction), Auger $\mathrm{WO}_{3}$ reference standard was cross-checked in stoichiometry by Raman spectroscopy and EDS. 


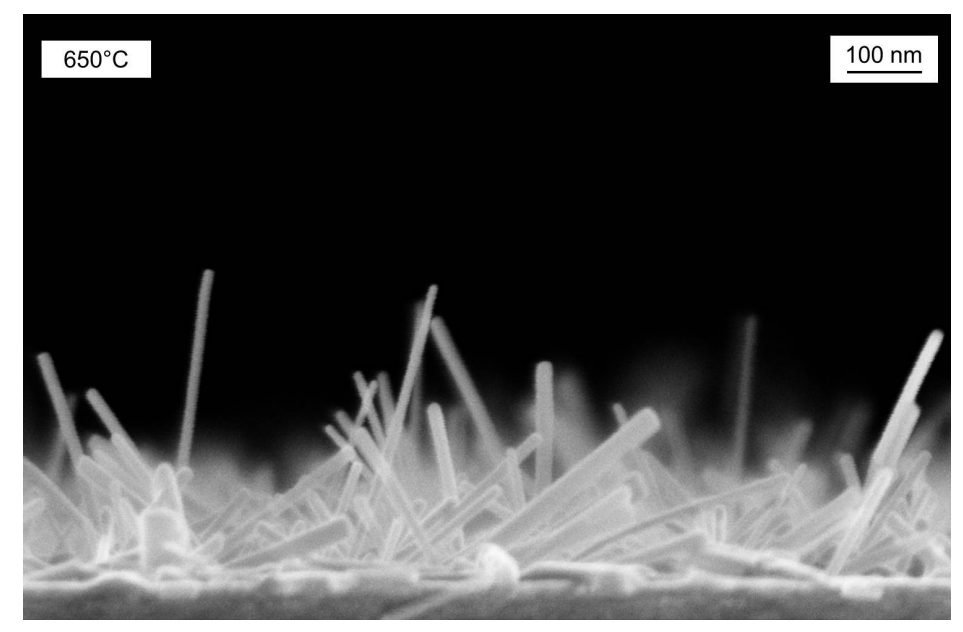

Figure 1. SEM image of NWs grown after vacuum annealing for $4 \mathrm{~h}$ at $650^{\circ} \mathrm{C}$ of a-W film with an $\mathrm{O}$ content of $33.5 \%$, deposited at $40 \mathrm{~Pa}$.

\section{Results}

An example of NWs nucleated at the surface of metastable a-W film, after thermal annealing in vacuum at $650^{\circ} \mathrm{C}$, is reported in Fig. 1. In this case the NWs are 340-400 $\mathrm{nm}$ long with a mean thickness of 20-40 nm, showing an aspect ratio of about 8-20. As explained below, the formation of NWs after vacuum annealing is made possible by the amorphous-like nature of the $\mathrm{W}$ coatings, which, beside owning an out-of-equilibrium structure, retain high amount of oxygen.

In section 3.1 crystalline disorder, oxygen distribution and the existence of oxidized phases of a-W films prior to the vacuum annealing are discussed.

In section 3.2 the features of the grown NWs (e.g. length, growth density and crystallographic phase) are presented, depending on process parameters like oxygen content, annealing time and temperature.

\subsection{Analysis of the $a-W$ film: oxygen amount and oxidation state}

W films deposited in vacuum exhibit a columnar growth and crystalline structure [21]. If background $\mathrm{He}$ gas is fed at either $40 \mathrm{~Pa}, 50 \mathrm{~Pa}$ or $75 \mathrm{~Pa}$ during the deposition of the a-W film, a morphology constituted of nanometric grains with random orientation is obtained. This kind of structure is called amorphous-like [21], see Fig. 2 (left). The corresponding XRD spectrum, see Fig. 2 (right), exhibits only a broad band centered around $2 \theta=40$ degrees over the whole range, with a full width at half maximum around 5 degrees. This value is compatible with the XRD bands of amorphous metallic alloys [21].

In the direct growth method the presence of an oxygen source is essential during NWs growth. Oxygen can either be present in the vacuum chamber as residual gas $[9,5]$, or it can be added intentionally as $\mathrm{O}_{2}$ flux $[19,11]$ or as $\mathrm{H}_{2} \mathrm{O}$ steam [12]. Amorphouslike $\mathrm{W}$ films can retain high amounts of interstitial oxygen, probably adsorbed at the 

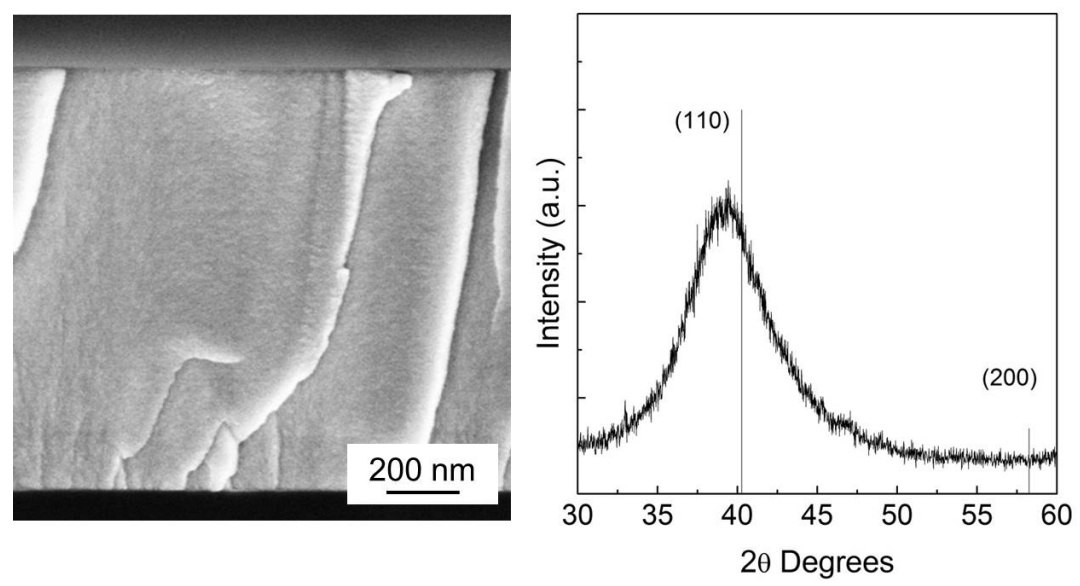

Figure 2. Left: SEM image of amorphous-like $\mathrm{W}$ film taken in cross section. Right: XRD spectrum of a-W, the broad band around 40 degrees is visible.
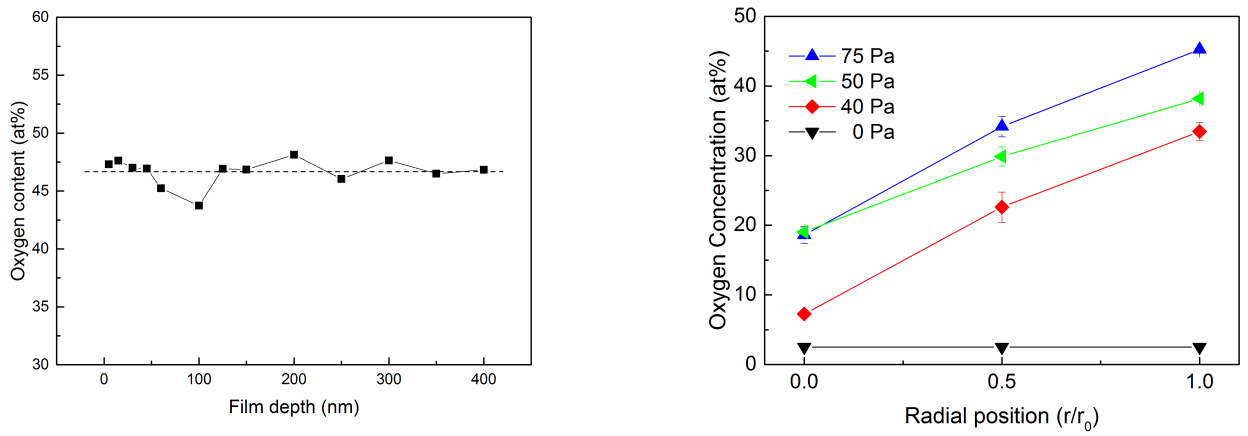

Figure 3. Characterization of oxygen content in the a-W film: (left) SAM depth profile analysis made at the periphery of a-W deposited at $75 \mathrm{~Pa}$ of He going from the surface to $400 \mathrm{~nm}$ (right) EDS analysis, investigated volume $100 \mathrm{~nm}$, ranging from center $\left(\mathrm{r} / r_{0}=0\right)$ to periphery $\left(\mathrm{r} / r_{0}=1\right)$ of a-W films deposited varying He pressure.

inter-granular volume. Oxygen is incorporated in the a-W matrix during the deposition process, where it is present as an impurity in the He gas, rather than reacting with $\mathrm{W}$ at film surface, after deposition, because of air exposure. This hypothesis is supported by results of SAM depth profiling analysis, shown in Fig. 3 (left). Oxygen concentration is constant in depth and no concentration gradients are appreciable along the cross section of the film. The amount of stored $\mathrm{O}$ in the $\mathrm{W}$ layer increases with the deposition pressure; the higher the pressure, the higher is the retained $\mathrm{O}$ amount [21]. In Fig. 3 (right) the elemental composition of the $\mathrm{W}$ films deposited at varying He pressure and radial position is presented, as characterized by EDS. In the columnar films, deposited in vacuum, oxygen concentration amounts to about $3 \%$ and does not depend on the radial position from the wafer center, towards which the PLD plume is oriented. Oxygen uptake is more relevant in the a-W films, and linearly increases in going from the center to the periphery of the wafer. This kind of oxygen distribution can be related to the dynamics of PLD deposition. During the PLD process, the He background gas interacts 


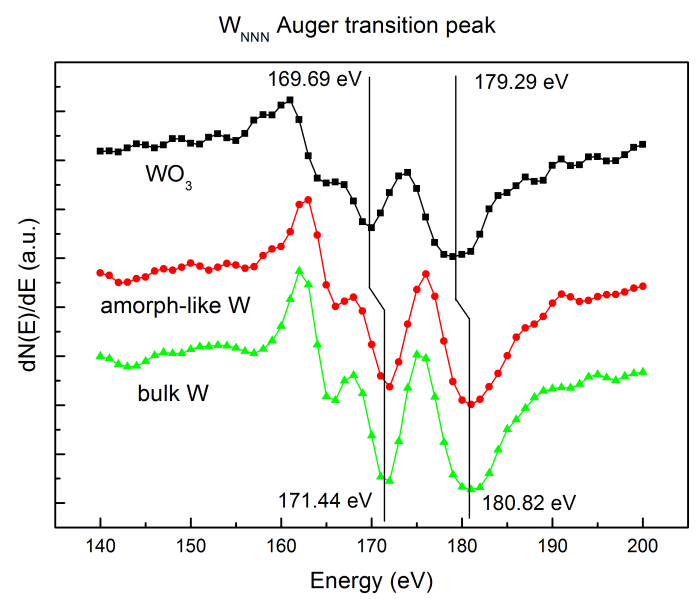

Figure 4. SAM analysis, W NNN spectra of bulk W, amorphous-like W and crystalline $\mathrm{WO}_{3}$.

with the different parts of the expanding plume and, consequently, the species arriving at the periphery of the deposit can be less energetic and less dense compared to those that form the central part of the film [24]. This inhomogeneity induces, besides a different film thickness, a gradient of oxygen concentration and, probably, a different grain's surface defects state. The richest oxygen region is the outer region of the deposit, where oxygen concentration ranges between $30 \%$ and $45 \%$ depending on He pressure.

In order to assess the condition of nucleation of NWs, it is of great interest to locally check for the existence of oxidized $\mathrm{W}$ phases in the a-W films. Auger spectra in Fig. 4 show the $\mathrm{W}(\mathrm{NNN})$ Auger transition peak around $180 \mathrm{eV}$ of the $\mathrm{W}$ metallic standard (bulk $\mathrm{W}$ ), of the $\mathrm{WO}_{3}$ reference and of the bulk of a-W film deposited at $40 \mathrm{~Pa}$. The $\mathrm{W}$ NNN Auger peak energy and line-shape measured on the a-W and the $\mathrm{W}$ metal surfaces are very similar, differently from the $\mathrm{WO}_{3}$ case where the peak energy is lower by a couple of eV and the line-shape is clearly different. This is an evidence of the metallic nature of the a-W and of the absence of chemical binding between the $\mathrm{W}$ and $\mathrm{O}$ atoms residing in the bulk [25].

In summary, among the W substrates which may promote NWs formation, PLD grown a-W thin films are promising candidates, due to out-of-equilibrium amorphous structure and the presence of large amounts of unbound oxygen in the $\mathrm{W}$ matrix.

\subsection{Producing $N W$ s by vacuum annealing of $a$ - $W$ films, role of process parameters}

Fig. 5 shows the SEM images collected on three regions, moving from the center to the periphery of the samples deposited at different He deposition pressure, after vacuum annealing at $650^{\circ} \mathrm{C}$ for 4 hours. In the labels the corresponding oxygen content, as determined by EDS before annealing, is also displayed. Growth of NWs seems to be affected by the features of a-W films, such as oxygen concentration and local defect state which in turn depend on He deposition pressure and radial position. 
Amorphous-like $\mathrm{W}$ films deposited at $40 \mathrm{~Pa}$ and $50 \mathrm{~Pa}$ promote NWs growth mainly in the middle region $\left(\mathrm{r} / \mathrm{r}_{0}=0.5\right)$ and at the periphery of the sample $\left(\mathrm{r} / \mathrm{r}_{0}=1\right)$. Radial distance from the center also influences density and length of the NWs. In general the central region is poorly populated by NWs; the most populated region is the one in the middle, while at the periphery the NWs grow less dense but longer than NWs grown in the middle region. This is not surprising as the film surface defects, that might act as nucleation centers, are non uniformly distributed, in ranging from center to periphery of the a-W films.

Also oxygen concentration plays a pivotal role in determining NWs nucleation. By considering a-W films deposited at $40 \mathrm{~Pa}$ and $50 \mathrm{~Pa}$ we can state that an oxygen concentration of $7.3 \%$ (averaged by the EDS probe over a volume of several $\mu^{3}$ ) does not allow NWs growth, whilst an O concentration between $19 \%$ and $38.2 \%$ allows NWs production.

On the other hand amorphous-like-W films deposited at $75 \mathrm{~Pa}$, substantially do not promote NWs development, except a weak growth in the middle region. A possible explanation of this inability is presented in the discussion section.

The dependence of NWs growth on the annealing temperature has been investigated, in the case of a sample presenting an $\mathrm{O}$ content of about $30 \%$ (at the periphery of an a-W film deposited at $40 \mathrm{~Pa}$ of $\mathrm{He}$ ), see Fig. 6. Below $450^{\circ} \mathrm{C}$, no NWs growth takes place, at $500-650^{\circ} \mathrm{C}$ NWs are detected, whilst the raise of the temperature up to $710^{\circ} \mathrm{C}$ leads to an increase of NWs density, at same NWs length. NWs synthesis temperatures reported in literature usually range between 650 and $1100^{\circ} \mathrm{C}$ [11]; in this range sublimation of NWs takes place, thus limiting NWs length to about $450 \mathrm{~nm}[19,18]$. On the other hand, in our case by using a-W, NWs growth takes place also at $500^{\circ} \mathrm{C}$, which is consistent with the typical onset of surface diffusion in $\mathrm{W}$, which is set around $130^{\circ} \mathrm{C}[26]$. We then performed a long annealing $(10 \mathrm{~h})$ at this temperature, with the aim of producing longer NWs. Some examples are displayed in Fig. 7. In this case the grown NWs are up to $0.85-3.6 \mu \mathrm{m}$ long, with thickness ranging between $20 \mathrm{~nm}$ and $40 \mathrm{~nm}$. The aspect ratio is therefore boosted to about 40-90.

As already discussed the length and density of NWs is related to their radial position. The central region, Fig. 7 a), is less populated than outer regions Fig. 7 b). Differently from the NWs synthesized by annealing for 4 hours at $650^{\circ} \mathrm{C}-710^{\circ} \mathrm{C}$, at the base of each NWs a nanoparticle (NP), of about $50 \mathrm{~nm}$, is present, see Fig. $7 \mathrm{c}$ ). It is known that metallic NPs are often used to catalyze NWs growth (e.g. Au NPs are used during the growth of Si NWs) following the Vapor Liquid Solid Growth scheme (VLS) [27], with the catalyst NPs ending at the top of the NWs. The presence of $\mathrm{WO}_{x} \mathrm{NPs}$ at the bottom of NWs has been addressed as auto catalyst VLS growth, as already observed in the synthesis of ZnO NWs. In this case after the formation of a NP, NWs nucleation and growth take place at the top of NPs $[28,29]$. In addition to the grown NWs it is also possible to see thicker nano-slab or nano-stripes [19, 30, 31, 32] that grow along the surface of the sample, see Fig. $7 \mathrm{~d}$ ). This kind of structure as been already detected during the NWs synthesis in other cases. 


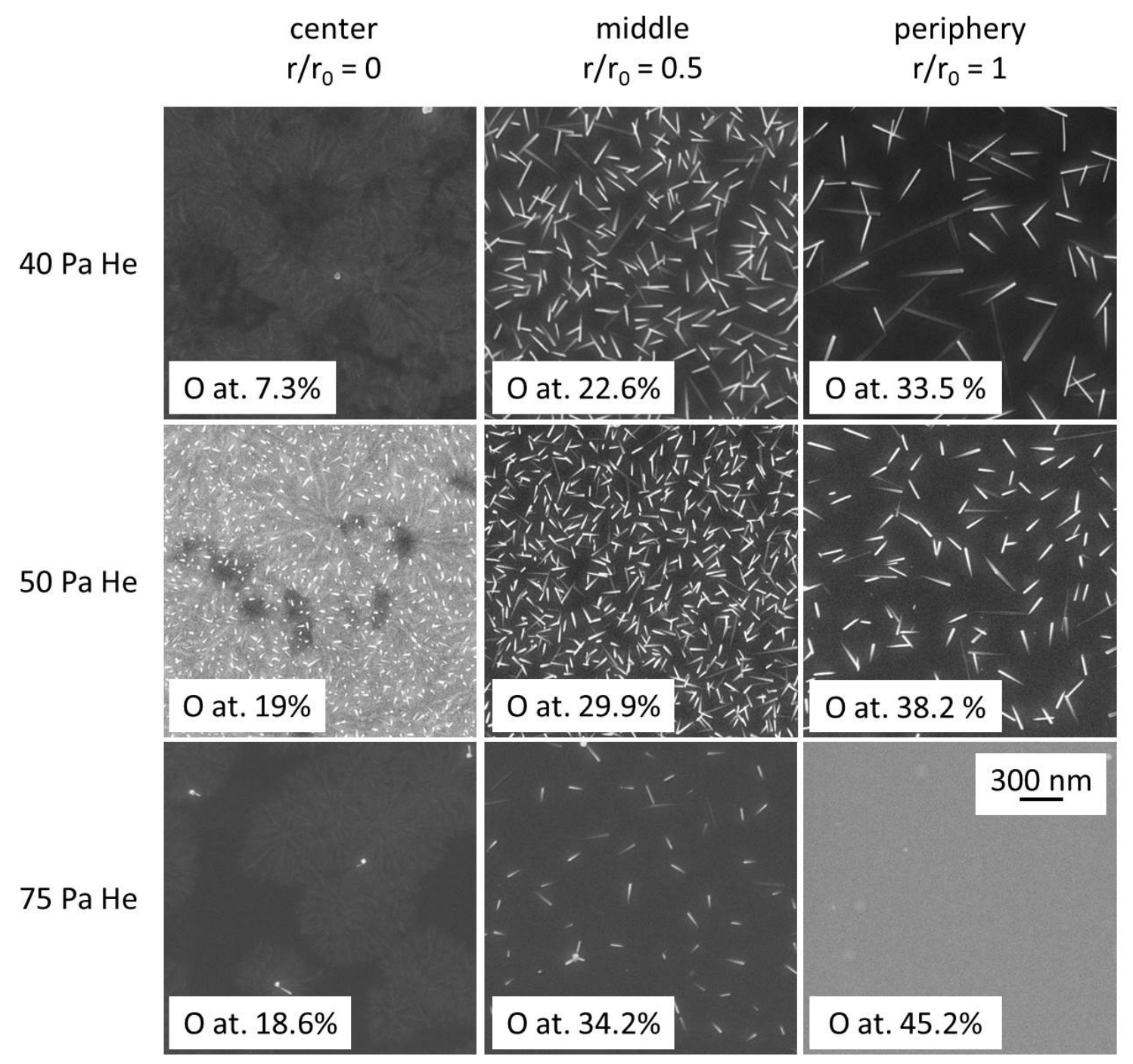

Figure 5. SEM secondary electron images and EDS analysis performed in different positions of the sample on a-W films, deposited at different He pressures, after annealing at $650^{\circ} \mathrm{C}$ for $4 \mathrm{~h}$.
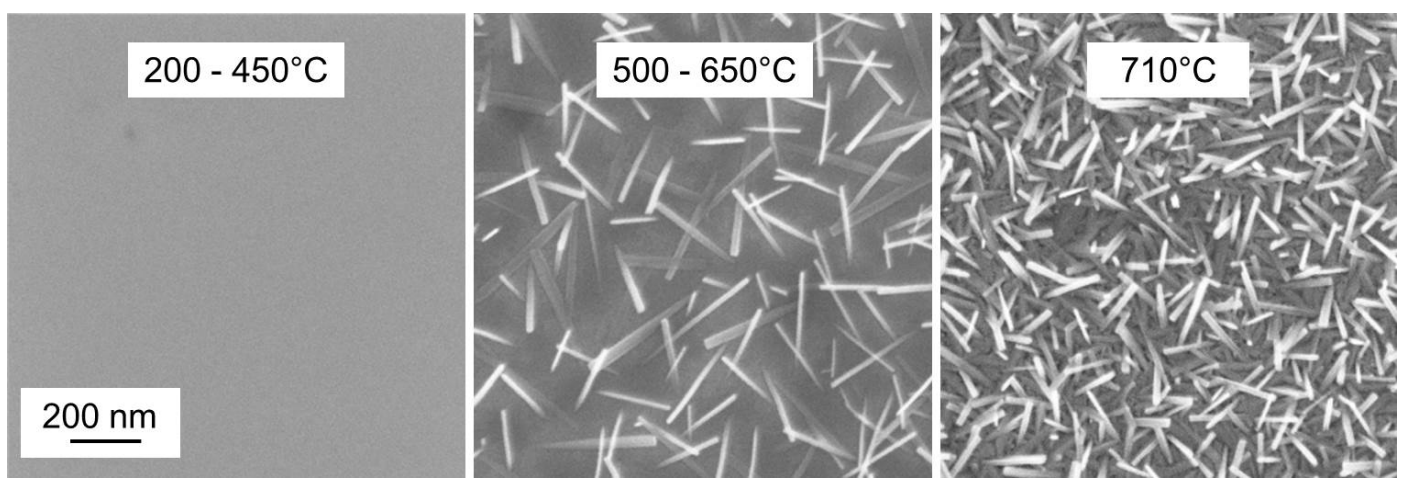

Figure 6. SEM image of NWs grown at the periphery of the a-W film, deposited at 40 $\mathrm{Pa}$, after vacuum annealing for $4 \mathrm{~h}$ at different annealing temperatures. The Oxygen content is $33.5 \%$. 


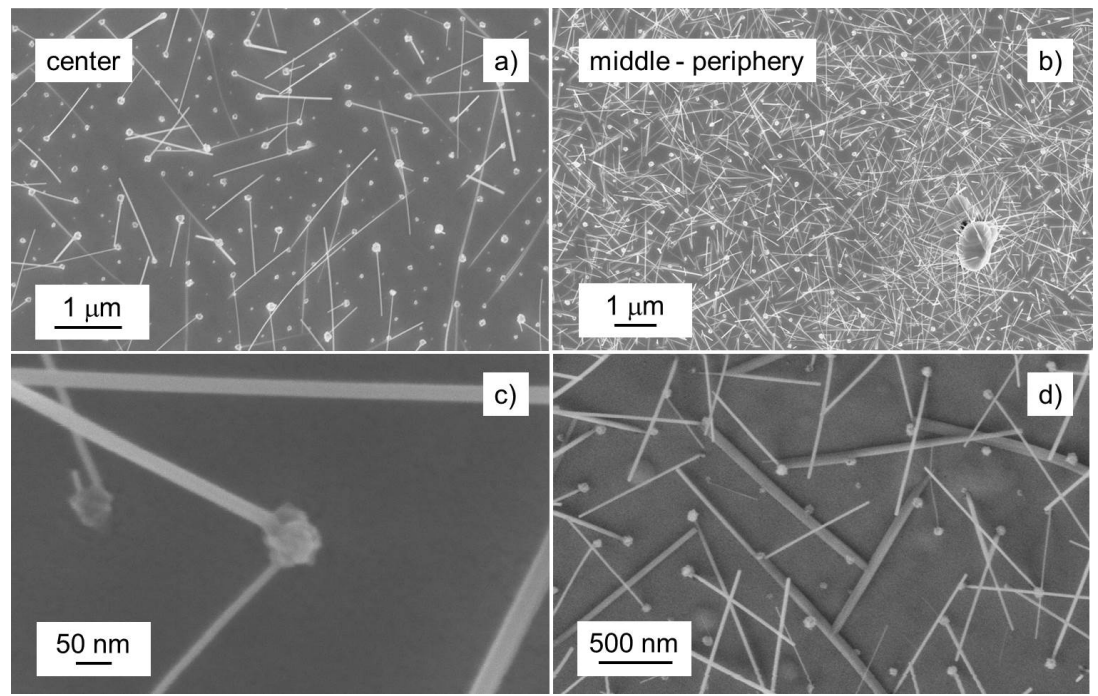

Figure 7. SEM image of $\mathrm{NW}$ grown after vacuum annealing at $500^{\circ} \mathrm{C}$, for $10 \mathrm{~h}$ : a) film center, b) middle and periphery of film, c) NPs at the base of NWs, d) nano-slabs
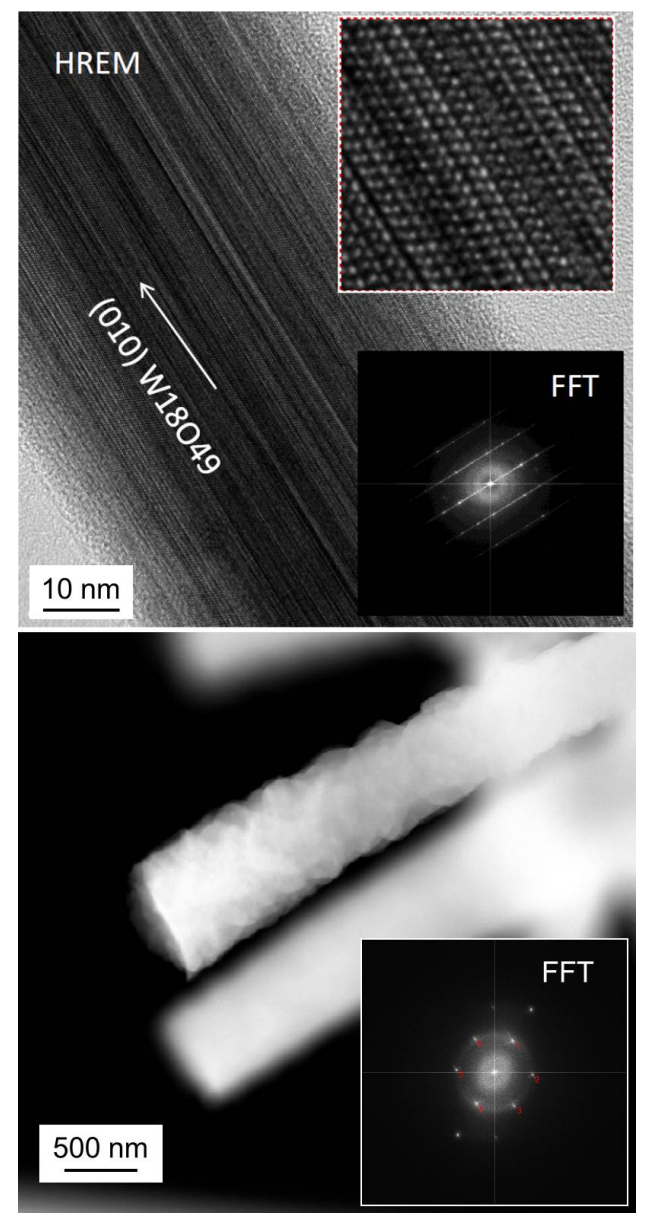

Figure 8. TEM images of $\mathrm{NW}$ grown at $500^{\circ} \mathrm{C}$ that exhibit the $\mathrm{W}_{18} \mathrm{O}_{49}$ structure (upper image) and $650^{\circ} \mathrm{C}$ (lower image) that exhibit the $\mathrm{WO}_{3}$ structure. The corresponding Fast Fourier Transform (FFT) are present in the insets. 


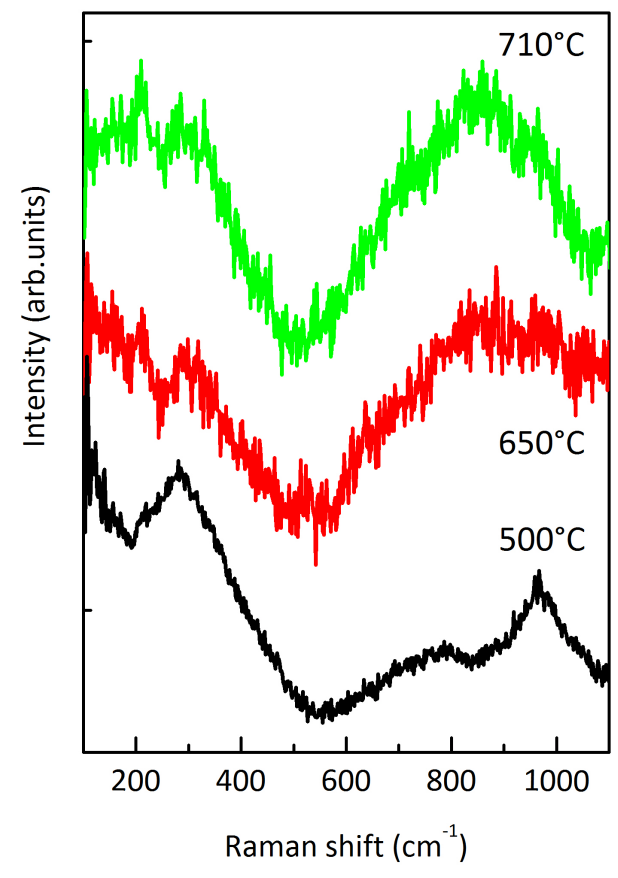

Figure 9. Raman analysis of the a-W films after being annealed at different temperatures.

The structure of NWs produced either at $500^{\circ} \mathrm{C}$ or at $650^{\circ} \mathrm{C}$ has been investigated using high resolution TEM, see Fig. 8. Both structures are of crystalline nature. The NWs grown at $500^{\circ} \mathrm{C}$ are highly regular and their thickness does not change on the whole length. They show the typical features of the $\mathrm{W}_{18} \mathrm{O}_{49}$ [33] phase, with a high degree of crystallinity. NWs grown at $650^{\circ} \mathrm{C}$ exhibit a different morphology. They are tapered, and thickness increases in proceeding from the base to the top. In addition, they are not regular and seem to be polycrystalline, while their crystalline structure has been assessed as monoclinic $\mathrm{WO}_{3}$ [34]. NWs features and stoichiometry have been characterized as well using Raman Spectroscopy. Characterization of films deposited at $40 \mathrm{~Pa}$ of $\mathrm{He}$ and annealed respectively at $500^{\circ} \mathrm{C}, 650^{\circ} \mathrm{C}$ and $710^{\circ} \mathrm{C}$, are shown in Fig. 9. Before annealing, no Raman signal is present, as expected for metallic tungsten. After vacuum annealing, only the films leading to NWs formation reveal a Raman signal that is related to the formation of tungsten oxide structures at the surface of the film. The lower spectrum in the figure refers to the long NWs obtained after annealing at $500{ }^{\circ} \mathrm{C}$ for 10 hours, while the other two spectra are related to annealing at $600{ }^{\circ} \mathrm{C}$ and 710 ${ }^{\circ} \mathrm{C}$ for 4 hours. As a general observation, all of them present a band-like aspect, as usually happens for disordered or confined systems [35]. Also a distribution of W-O-W bond lengths, as suggested for $\left(\mathrm{WO}_{3-x}\right)$ NWs, can account for broad featureless bands $[36,37]$. More in details spectra are characterized by a low frequency band below 500 
$\mathrm{cm}^{-1}$, related to O-W-O bending modes, and a high frequency band, between 600 and $1000 \mathrm{~cm}^{-1}$, attributed to W-O stretching modes [38]. The spectrum of NWs annealed at $500{ }^{\circ} \mathrm{C}$ appears to be different from the two others. Firstly the high frequency band is less intense than the low frequency band as expected in case of sub-stoichiometric oxide $[2,38]$. This is in agreement with the TEM attribution of these NWs to the $\mathrm{W}_{18} \mathrm{O}_{49}$ phase. Moreover this band appears to be divided into two broad feature, where the one at about $950 \mathrm{~cm}^{-1}$ is usually attributed to $\mathrm{W}=\mathrm{O}$ stretching modes at grain boundaries and surfaces [38], hence compatible with the high aspect ratio of these long NWs. In the two other spectra the two bands are more symmetric, as is usual in the case of stoichiometric oxide, confirming that in these cases the NWs are composed mostly by $\mathrm{WO}_{3}$ nanocrystals.

The most common crystallographic phase for the NWs grown in needle-like structures is $\mathrm{W}_{18} \mathrm{O}_{49}$ [12]. Nevertheless, depending on the growth method it is also possible to obtain $\mathrm{WO}_{3} \mathrm{NWs}$ with different crystalline phases: monoclinic [39, 2], triclinic [40] and hexagonal [41]. Therefore, it is possible that during the annealing of a-W the different annealing temperatures trigger different local condition at the surface and different reaction kinetics which, in turn, promote the formation of different crystalline phases and structures. In particular at high temperature, $600{ }^{\circ} \mathrm{C}-710{ }^{\circ} \mathrm{C}$, fast dynamic leads to the formation of polycrystalline $\mathrm{WO}_{3}$ needle-like structures. Annealing at low temperatures, $500{ }^{\circ} \mathrm{C}$, allows the synthesis of much ordered structures via a two step synthesis. Firstly $\mathrm{WO}_{x}$ nanoparticles grow on the $\mathrm{W}$ surface. Subsequently from the facets of the nanoparticles the development of highly crystalline $\mathrm{W}_{18} \mathrm{O}_{49}$ NWs occurs.

To summarize, the annealing of a-W layers determines a new kind of NWs synthesis whose main features are:

- micrometer long NWs up to $3.6 \mu \mathrm{m}$;

- reaction temperature in the range $500^{\circ} \mathrm{C}-710^{\circ} \mathrm{C}$. This interval allows lower synthesis temperatures compared with other cases [19, 11, 10];

- no gas flow is required, the proper oxygen amount, determined by deposition parameters, is already present in the a-W film;

- variable crystalline structures in dependence on annealing temperature: at $500^{\circ} \mathrm{C}$ the NWs exhibit the $\mathrm{W}_{18} \mathrm{O}_{49}$ crystalline structure, at $650^{\circ} \mathrm{C}$ it changes to $\mathrm{WO}_{3}$;

\section{Discussion}

As already discussed in the introduction, although the mechanism of nucleation of NWs from $\mathrm{W}$ surface is not fully understood, in the literature their growth has been related to the existence of an interfacial stress field between an outward $\mathrm{WO}_{x}$ layer at the surface and the $\mathrm{W}$ matrix. NWs growth would convert strained oxide at the $\mathrm{W} / \mathrm{WO}_{x}$ interface to unstrained oxide in the NWs $[6,10]$.

In the present case, the strain may be induced by a different situation, that is the formation of a crystalline $\mathrm{W}$ phase in the underlying amorphous-like $\mathrm{W}$ matrix. In Fig. 

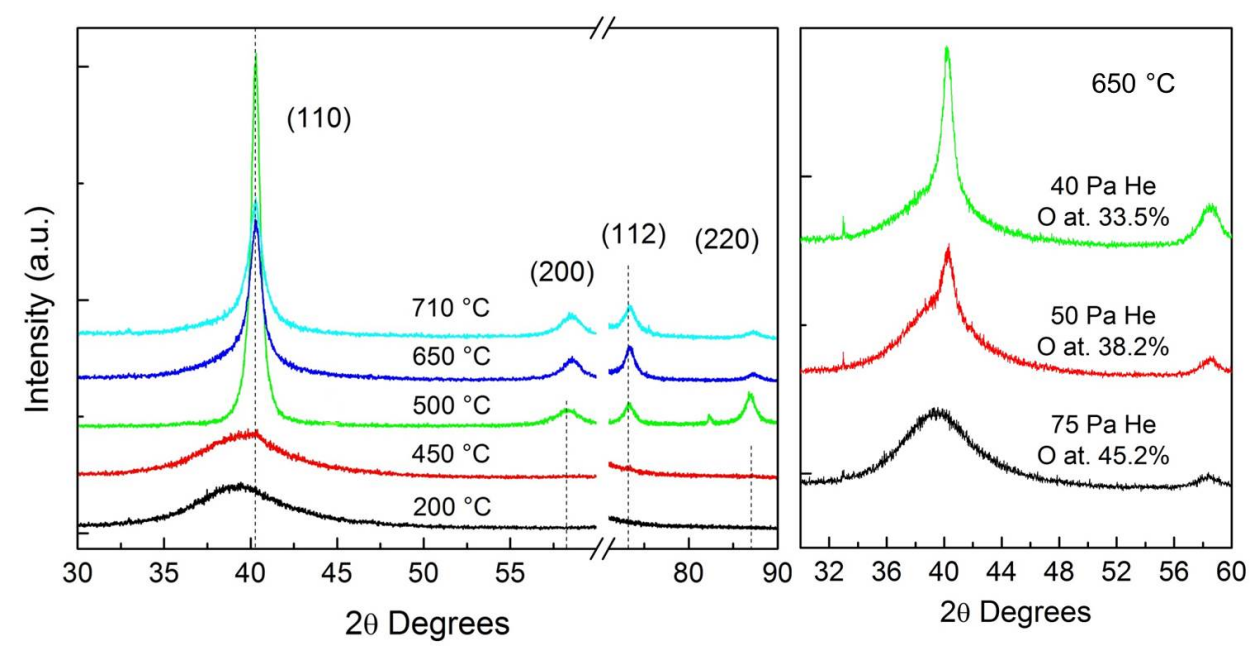

Figure 10. left: XRD spectra of a-W deposited at $40 \mathrm{~Pa}$, annealing time $4 \mathrm{~h}$, varying annealing temperature. right: XRD spectra of a-W samples annealed at $650^{\circ} \mathrm{C}$ raising oxygen content. The peak around 40 degrees has been related to the (110) reflection of $\alpha$ crystalline $\mathrm{W}$ phase

10 (left) the XRD spectrum of the a-W layer, deposited at $40 \mathrm{~Pa}$, at different annealing temperature is reported. Below $500^{\circ} \mathrm{C}$, that is the threshold temperature for NWs formation, the a-W film is amorphous and shows a broad band around $2 \theta=40$ degrees. As temperature increases above $500^{\circ} \mathrm{C}$, XRD reflections appear, does indicating the nucleation of the $\alpha$-W crystalline phase embedded in the metastable a-W film. Due to its amorphous structure the crystallization temperature for a- $\mathrm{W}$ is much lower than the corresponding recrystallization temperature for bulk microcrystalline W (about 1300$\left.1500^{\circ} \mathrm{C}\right)[22]$. The crystallization of the metastable a-W films, in regions with proper oxygen concentration, will be associated to some amount of stress at interface and therefore may induce NWs synthesis already at $500^{\circ} \mathrm{C}$.

The correlation between NWs production and a-W crystallization is further confirmed by XRD analysis performed on a-W films annealed at $650^{\circ} \mathrm{C}$ for $4 \mathrm{~h}$, in samples deposited at various deposition pressures, as shown in Fig. 10 (right). The corresponding SEM images are displayed in Fig. 5. Films deposited at $40 \mathrm{~Pa}$ and $50 \mathrm{~Pa}$ lead to the formation of NWs differently from films deposited at $75 \mathrm{~Pa}$. After annealing, the a-W films deposited at $40 \mathrm{~Pa}$ and $50 \mathrm{~Pa}$ crystallize as the (110) reflection of the $\alpha$-W phase is visible, but there is nearly no crystallization for the film deposited at $75 \mathrm{~Pa}$ of He. The (110) reflection is not visible and only a small band related to the (200) reflection can be appreciated. One possible explanation may be related to the highest oxygen content in the a-W films deposited at $75 \mathrm{~Pa}$. It is known that oxygen plays a fundamental role in stabilizing $\mathrm{W}$ structures like $\beta-\mathrm{W}$ and $\mathrm{a}-\mathrm{W}[22]$. In fact, the raise in the amount of oxygen in the a-W film leads to a decrease in the intensity of $\alpha$-W reflections in the annealed films as shown in Fig. 10 (right). 


\section{Conclusions}

Tungsten oxide NWs were nucleated at the surface of a-W layers by vacuum annealing. The a-W films were deposited by PLD in the presence of He gas. Thanks to the amorphous structure, the oxygen needed for the NWs synthesis is already embedded in the a-W matrix, in dependence on deposition parameters (i.e. He pressure). NWs growth takes place at oxygen concentration ranging between $20 \%$ and $40 \%$ and is promoted by vacuum heating of $\mathrm{W}$, from $500^{\circ} \mathrm{C}$ to $710^{\circ} \mathrm{C}$. NWs length and surface density are related to the surface morphology of the annealed a- $\mathrm{W}$ film. The crystalline structure of NWs depends on annealing temperature, ranging from $\mathrm{W}_{18} \mathrm{O}_{49}$ - Magneli phase to monoclinic $\mathrm{WO}_{3}$. Long annealing times $(10 \mathrm{~h})$, at $500^{\circ} \mathrm{C}$, induce the formation of NWs up to $3.6 \mu \mathrm{m}$ long. NWs growth appears to be related to the formation of the crystalline $\alpha$-W phase in the underlying a-W film, at temperatures well below the recrystallization temperature of bulk $\mathrm{W}$. The production of micrometer long NWs at low temperature (i.e. $500^{\circ} \mathrm{C}$ ) through a process so simple as vacuum annealing of a-W films, may allow the direct integration of NWs on silicon chips.

\section{Bibliography}

[1] Fenster C, Smith AJ, Abts A, Milenkovic S, Hassel AW. Single tungsten nanowires as pH sensitive electrodes. Electrochemistry Communications. 2008;10(8):1125 - 1128.

[2] Ponzoni A, Russo V, Bailini A, Casari CS, Ferroni M, Li Bassi A, Migliori A, Morandi V, Ortolani L, Sberveglieri G, Bottani CE. Structural and gas-sensing characterization of tungsten oxide nanorods and nanoparticles. Sensors and Actuators B: Chemical. 2011 Apr;153(2):340-346.

[3] Deb B, Desai S, Sumanasekera GU, Sunkara MK. Gas sensing behaviour of mat-like networked tungsten oxide nanowire thin films. Nanotechnology. 2007 Jul;18(28):285501.

[4] Reyes-Gil KR, Wiggenhorn C, Brunschwig BS, Lewis NS. Comparison between the Quantum Yields of Compact and Porous WO3 Photoanodes. The Journal of Physical Chemistry C. 2013;117(29):14947-14957.

[5] Liu J, Zhang Z, Zhao Y, Su X, Liu S, Wang E. Tuning the Field-Emission Properties of Tungsten Oxide Nanorods. Small. 2005;1(3):310-313.

[6] Seelaboyina R, Huang J, Park J, Kang DH, Choi WB. Multistage field enhancement of tungsten oxide nanowires and its field emission in various vacuum conditions. Nanotechnology. 2006 Oct;17(19):4840-4844.

[7] Yue S, Pan H, Ning Z, Yin J, Wang Z, Zhang G. Amazing ageing property and in situ comparative study of field emission from tungsten oxide nanowires. Nanotechnology. 2011 Mar;22(11):115703.

[8] Chang MT, Chou LJ, Chueh YL, Lee YC, Hsieh CH, Chen CD, et al. Nitrogen-doped tungsten oxide nanowires: low-temperature synthesis on $\mathrm{Si}$, and electrical, optical, and field-emission properties. Small (Weinheim an der Bergstrasse, Germany). 2007 Apr;3(4):658-64.

[9] Gu G, Zheng B, Han WQ, Roth S, Liu J. Tungsten Oxide Nanowires on Tungsten Substrates. Nano Letters. 2002 Aug;2(8):849-851.

[10] Klinke C, Hannon JB, Gignac L, Reuter K, Avouris P. Tungsten oxide nanowire growth by chemically induced strain. The journal of physical chemistry B. 2005 Sep;109(38):17787-90.

[11] Kojima Y, Kasuya K, Nagato K, Hamaguchi T, Nakao M. Solid-phase growth mechanism of tungsten oxide nanowires synthesized on sputtered tungsten film. Journal of Vacuum Science \& Technology B: Microelectronics and Nanometer Structures. 2008;26(6):1942.

[12] Pfeifer J, Badaljan E, Tekula-Buxbaum P, Kovacs T, Geszti O, a L Toth, et al. Growth 
and morphology of W18049 crystals produced by microwave decomposition of ammonium paratungstate. Journal of Crystal Growth. 1996 Dec;169(4):727-733.

[13] Zhang X, Gong L, Liu K, Cao Y, Xiao X, Sun W, et al. Tungsten oxide nanowires grown on carbon cloth as a flexible cold cathode. Advanced materials (Deerfield Beach, Fla). 2010 Dec;22(46):5292-6.

[14] Zhou J, Ding Y, Deng SZ, Gong L, Xu NS, Wang ZL. Three-Dimensional Tungsten Oxide Nanowire Networks. Advanced Materials. 2005 Sep;17(17):2107-2110.

[15] Liu J, Zhao Y, Zhang Z. Low-temperature synthesis of large-scale arrays of aligned tungsten oxide nanorods. Journal of Physics: Condensed Matter. 2003;15(29):L453.

[16] Xi G, Ouyang S, Li P, Ye J, Ma Q, Su N, et al. Ultrathin W18O49 nanowires with diameters below $1 \mathrm{~nm}$ : synthesis, near-infrared absorption, photoluminescence, and photochemical reduction of carbon dioxide. Angewandte Chemie (International ed in English). 2012 Mar;51(10):2395-9.

[17] Sun S, Zou Z, Min G. Synthesis of bundled tungsten oxide nanowires with controllable morphology. Materials Characterization. 2009 May;60(5):437-440.

[18] Jeon S, Yong K. Direct synthesis of W 18 O 49 nanorods from W 2 N film by thermal annealing. Nanotechnology. 2007 Jun;18(24):245602.

[19] Chen CH, Wang SJ, Ko RM, Kuo YC, Uang KM, Chen TM, et al. The influence of oxygen content in the sputtering gas on the self-synthesis of tungsten oxide nanowires on sputter-deposited tungsten films. Nanotechnology. 2006 Jan;17(1):217-223.

[20] Yu W, Pan C. Low temperature thermal oxidation synthesis of $\mathrm{ZnO}$ nanoneedles and the growth mechanism. Materials Chemistry and Physics. 2009 May;115(1):74-79.

[21] Dellasega D, Merlo G, Conti C, Bottani CE, Passoni M. Nanostructured and amorphous-like tungsten films grown by pulsed laser deposition. Journal of Applied Physics. 2012;112(8):084328.

[22] Radic N, Tonejc A, Ivkov J, Dubcek P, Bernstorff S, Medunic Z. Sputter-deposited amorphous-like tungsten. Surface and Coatings Technology. 2004;180-181:66-70.

[23] Metaferia W, Sun Y-T, Pietralunga S M, Zani M, Tagliaferri A, Lourdudoss S. Polycrystalline indium phosphide on silicon by indium assisted growth in hydride vapor phase epitaxy. Journal of Applied Physics. 2014;116(3):033519.

[24] Kang DW, Jeon IJ, Song JS, Kim D. Spatial and energy distribution of Co, Ag and Pt particles in pulsed laser deposition: in view of the fabrication of nanometer multilayer film. Applied Physics A: Materials Science \& Processing. 2003 Aug;77(3-4):449-453.

[25] Powell C J. Recommended Auger parameters for 42 elemental solids. Journal of Electron Spectroscopy And Related Phenomena. 2012;185(1-2):1-3.

[26] Tringides M C. Surface Diffusion: Atomistic and Collective Processes. Springer Science \& Business Media, Nov 11, 2013.

[27] Wagner R S, Ellis W C. Vapor-Liquid-Solid mechanism of single crystal growth. Applied Physics Letters. 1964;4: 89-90.

[28] Yu D, Trad T, McLeskey J T Jr, Craciun V, Taylor C R. ZnO Nanowires Synthesized by Vapor Phase Transport Deposition on Transparent Oxide Substrates. Nanoscale Research Letters. 2010;5(8):1333-1339.

[29] Geng C, Jiang Y, Yao Y, Meng X, Zapien J A, Lee C S, Lifshitz Y, Lee S T. Well-Aligned $\mathrm{ZnO}$ Nanowire Arrays Fabricated on Silicon Substrates. Advanced Functional Materials. 2004;14(6):589-594.

[30] Shi S, Xue X, Feng P, Liu Y, Zhao H, Wang T. Low-temperature synthesis and electrical transport properties of W18O49 nanowires. Journal of Crystal Growth. 2008 Jan;310(2):462-466.

[31] Hsieh YT, Chen US, Hsueh SH, Huang MW, Shih HC. Rapid formation of tungsten oxide nanobundles with controllable morphology. Applied Surface Science. 2011 Feb;257(8):35043509 .

[32] Meng D, Shaalan NM, Yamazaki T, Kikuta T. Preparation of tungsten oxide nanowires and their application to NO2 sensing. Sensors and Actuators B: Chemical. 2012 Jul;169(2):113-120.

[33] JCPDS Card No. 36-101 and 5-392. 
[34] JCPDS Card No. 5-363.

[35] Shuker R, Gammon R. Physical Review Letters. 1970;25:222-225.

[36] Lu DY, Chen J, Deng SZ, Xu NS, Zhang WH. J Mater Res. 2008;23:402-408.

[37] Frey GL, Rothschild A, Sloan J, Rosentsveig R, Popovitz-Biro R, Tenne R. Journal of Solid State Chemistry. 2001;162:300-314.

[38] Di Fonzo F, Bailini A, Russo V, Baserga A, Cattaneo D, Beghi MG, et al. Catalysis Today. $2006 ; 116: 69-73$.

[39] Li L, Zhang Y, Fang X, Zhai T, Liao M, Sun X, et al. WO3 nanowires on carbon papers: electronic transport, improved ultraviolet-light photodetectors and excellent field emitters. Journal of Materials Chemistry. 2011;21(18):6525.

[40] Hsieh YT, Huang MW, Chang CC, Chen US, Shih HC. Growth and optical properties of uniform tungsten oxide nanowire bundles via a two-step heating process by thermal evaporation. Thin Solid Films. 2010 Dec;519(5):1668-1672.

[41] Huirache-Acuña R, Paraguay-Delgado F, Albiter Ma, Lara-Romero J, Martínez-Sánchez R. Synthesis and characterization of WO3 nanostructures prepared by an aged-hydrothermal method. Materials Characterization. 2009 Sep;60(9):932-937. 